\title{
Operative techniques in awake coronary artery bypass grafting
}

\author{
Tayfun Aybek, MDa \\ P. Kessler, MD, $\mathrm{PhD}^{\mathrm{b}}$ \\ M. F. Khan, $\mathrm{MD}^{\mathrm{a}}$ \\ S. Dogan, $M D^{a}$ \\ G. Neidhart, $M D^{b}$ \\ A. Moritz, MD, PhD \\ G. Wimmer-Greinecker, $\mathrm{MD}, \mathrm{PhD}^{\mathrm{a}}$
}

See related articles on pages 1204, 1401, and 1526.
From the Department of Thoracic and Cardiovascular Surgery, ${ }^{\mathrm{a}}$ and the Department of Anesthesiology, Intensive Care and Pain

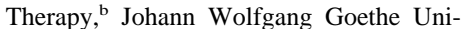
versity, Frankfurt, Germany.

Received for publication May 26, 2002; revisions requested July 12, 2002; revisions received Aug 28, 2002; accepted for publication Sept 9, 2002

Address for reprints: Tayfun Aybek, MD, Department of Thoracic and Cardiovascular Surgery, Johann Wolfgang Goethe University Frankfurt, Theodor Stern Kai 7, 60590 Frankfurt, Germany (E-mail: T.Aybek@em.uni-frankfurt.de).

J Thorac Cardiovasc Surg 2003;125: $1394-400$

Copyright $\odot 2003$ by The American Association for Thoracic Surgery

$0022-5223 / 2003 \$ 30.00+0$

doi:10.1016/S0022-5223(02)73607-6
Background: Off-pump coronary artery bypass grafting was implemented to reduce trauma of surgical coronary revascularization by avoiding extracorporeal circulation. High thoracic epidural anesthesia further reduces intraoperative stress and postoperative pain. In addition, this technique even allows awake coronary artery bypass grafting, avoiding the drawbacks of mechanical ventilation and general anesthesia in high-risk patients.

Methods: Thirty-four patients underwent awake coronary artery bypass grafting with left internal thoracic artery to left anterior descending coronary artery by partial lower ministernotomy $(n=20)$, H-graft technique $(n=2)$, or rib cage-lifting technique $(n=2)$. In 9 cases we performed double bypass grafting, and in 1 case we performed triple-vessel coronary artery revascularization through complete median sternotomy. In addition to clinical outcomes, visual analog scale pain scores were recorded on days 1,2 , and 3 after surgery.

Results: Thirty-one patients remained awake throughout the whole procedure. Three patients required secondary intubation because of incomplete analgesia $(n=1)$ or pneumothorax $(\mathrm{n}=2)$. Procedure time was $90 \pm 31$ minutes, and recovery room stay was $4.2 \pm 0.6$ hours. There were no in-hospital deaths or serious postoperative complications. In 1 case a graft occlusion was documented on predischarge angiography. Early postoperative pain was low (visual analog scale score of $30 \pm 6$ ).

Conclusion: These data demonstrate the feasibility and safety of various surgical coronary revascularization techniques without general anesthesia. Continuation of thoracic epidural analgesia provides good pain control and fast mobilization postoperatively. Surprisingly, the awake coronary artery bypass grafting procedure was well accepted by the patients.

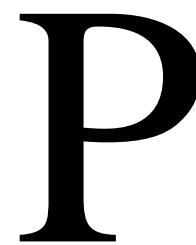
rocedures to minimize surgical, anesthesiologic, or cardiopulmonary bypass trauma during cardiac operations are in continuous development in an effort to reduce perioperative mortality and morbidity. The current technique of beating-heart coronary artery bypass grafting (CABG) is intended to decrease the adverse side effects typically associated with cardiopulmonary bypass, ${ }^{1,2}$ resulting in reductions in morbidity and length of hospital stay.,

The perioperative use of high thoracic epidural anesthesia (TEA) and analgesia in patients undergoing cardiac surgery leads to stress-response attenuation, intense perioperative analgesia, cardiac sympatholysis and thus improved vascular graft blood flow, and improved postoperative pulmonary and gastrointestinal function, 
with concomitant decreases in morbidity and mortality. ${ }^{5-9}$ Somatosensory block of the thoracic segments even enables sternotomy and CABG in the awake setting. ${ }^{10-13}$ In addition to these intraoperative advantages, postoperative pain management is facilitated by continuous epidural application of analgesics. Such effective pain management improves postoperative mobilization and recovery. The risks associated with TEA are infection and hematoma in rare cases. Reports state a risk of peridural hematoma or infection of 1:50,000 to $1: 100,000 .^{14,15}$ The potential problems associated with endotracheal intubation, such as trauma to teeth or vocal cords and or peri-intubational hypoxia, are absent. Patients with certain risk profiles, including chronic obstructive pulmonary disease, coagulation disorders, and aberrant neurologic conditions, seem to benefit most from operations without cardiopulmonary bypass. ${ }^{16}$ However, significant complications after on-pump CABG are still often associated with preexisting pulmonary disease or reduced general status. Such complications often necessitate prolonged postoperative ventilatory support and intensive care unit stay. With awake CABG (ACAB), the risk of postoperative pulmonary failure and long-term ventilation may be reduced because positive-pressure ventilation is avoided.

Some patients have hemodynamic compromise as a result of narcotic medication before intubation, which carries the risk of preoperative myocardial ischemia or infarction in patients with severe coronary artery disease. ${ }^{17}$ This also may be avoided in the conscious setting.

It therefore seems obviously beneficial to combine the advantages of beating-heart surgery with TEA, which enables CABG in the awake patient as first reported by Karagöz and associates. ${ }^{10}$ Various operative techniques have been described to accomplish ACAB. ${ }^{11-13}$ We evaluated these new techniques and also patient acceptance.

\section{Patients and Methods}

Between March 2001 and April 2002, a total of 34 CABG procedures with TEA in conscious patients were performed at our clinic. Written informed consent was obtained from all patients. Patient selection criteria included restriction to significant $(>70 \%)$ stenoses of the left anterior descending coronary artery (LAD), diagonal branches, or the right coronary artery (RCA), as well as good patient compliance. Presence of comorbidity did not affect patient selection except for impaired lung function (forced expiratory volume in 1 second $<50 \%$ ). Patients receiving platelet-inhibiting drugs and those undergoing emergency operations were excluded from the awake approach.

Demographic data and preoperative conditions of patients are described in Table 1. Twenty-five patients had significant comorbidity, such as severe obstructive lung disease, peripheral vascular disease, renal failure, and diabetes. To assess the preoperative risk of each patient, the EuroSCORE was determined. ${ }^{18}$ Assessment of perioperative myocardial ischemia was performed by assessing creatine kinase (CK) MB levels and 5-lead to 12-lead electrocardiography from 1 and 6 hours after the operation. Postoperative

\section{TABLE 1. Demographic characteristics}

Age (y, mean \pm SD)

Sex ratio (female/male)

Body surface area $\left(\mathrm{m}^{2}\right.$, mean $\left.\pm \mathrm{SD}\right)$

Preoperative Canadian Cardiovascular

Society ${ }^{10}$ (mean \pm SD)

Left ventricular ejection fraction $1 \%$, mean \pm SD)

Previous myocardial infarction (No.)

Chronic obstructive lung disease (No.)

Renal disease (No.)

Dialysis (No.)

Peripheral vascular disease (No.)

Diabetes mellitus (No.)

Risk score (EuroSCORE, mean \pm SD)

High-risk patients (No.)
$65.2 \pm 9.1$
$8: 26$
$1.96 \pm 0.13$
$3.0 \pm 0.6$
$60 \pm 8$

8 9

7

2

8

9

$3.8 \pm 2.0$

9 pain perception was documented with the visual analog scale. ${ }^{19}$ Patients mobilization after surgery was assessed by performing activities of daily life tests. $^{20}$

\section{Statistical Analysis}

All data were reviewed prospectively. Data are expressed as mean \pm SD. Descriptive statistical analysis was done with the StatView statistical software package 5.0.1 (SAS Institute, Inc, Cary, NC).

\section{Operative Techniques for ACAB}

Partial lower sternotomy. In 20 cases we used the partial lower sternotomy approach without cardiopulmonary bypass and endotracheal anesthesia. The patients were placed in a supine position and prepared as for conventional cardiac surgical procedures. A vertical skin incision was made from the fourth intercostal space to the xiphoid process $(7-8 \mathrm{~cm})$. The lower half of the sternum was then divided up into the third left intercostal space, starting from the xiphoid process, with an oscillating saw. A small pediatric thorax retractor (Aeskulap, Tüttlingen, Germany) was used for exposition and harvesting of the left internal thoracic artery (LITA). After dissection of the LITA in conventional technique without opening the pleural cavity, the pericardium was opened. Heparin was given in a standard dose of 10,000 IU. Deep pericardial sutures were placed near the left pulmonary vein to pull the pericardium upward and bring up the LAD to the surgical field. In 10 patients we used a pressure-type stabilizer (Baxter Healthcare Corporation CardioVascular Group, Irvine, Calif) for the anastomosis. The anastomotic site of the LAD was chosen, and a 4-0 SH polypropylene suture (Ethicon, Norderstedt, Germany) was passed around proximally to the anastomotic site of the LAD for control of proximal bleeding with a small tourniquet. Ischemic preconditioning was used to confirm hemodynamic stability before proceeding with the arteriotomy and grafting, except in cases with total LAD occlusion. The LAD was opened longitudinally $7 \mathrm{~mm}$, and the proximal suture was snared gently to obtain hemostasis. The LITA-LAD anastomosis was carried out with 8-0 polypropylene suture in a continuous fashion. A $75 \%$ dose of protamine was given at the end of surgery. After insertion of two drains into the pericardial cavity $(24 \mathrm{~F})$ and the substernal space $(28 \mathrm{~F})$, the lower sternotomy was closed with sternal wires and the soft tissue was closed in layers. 

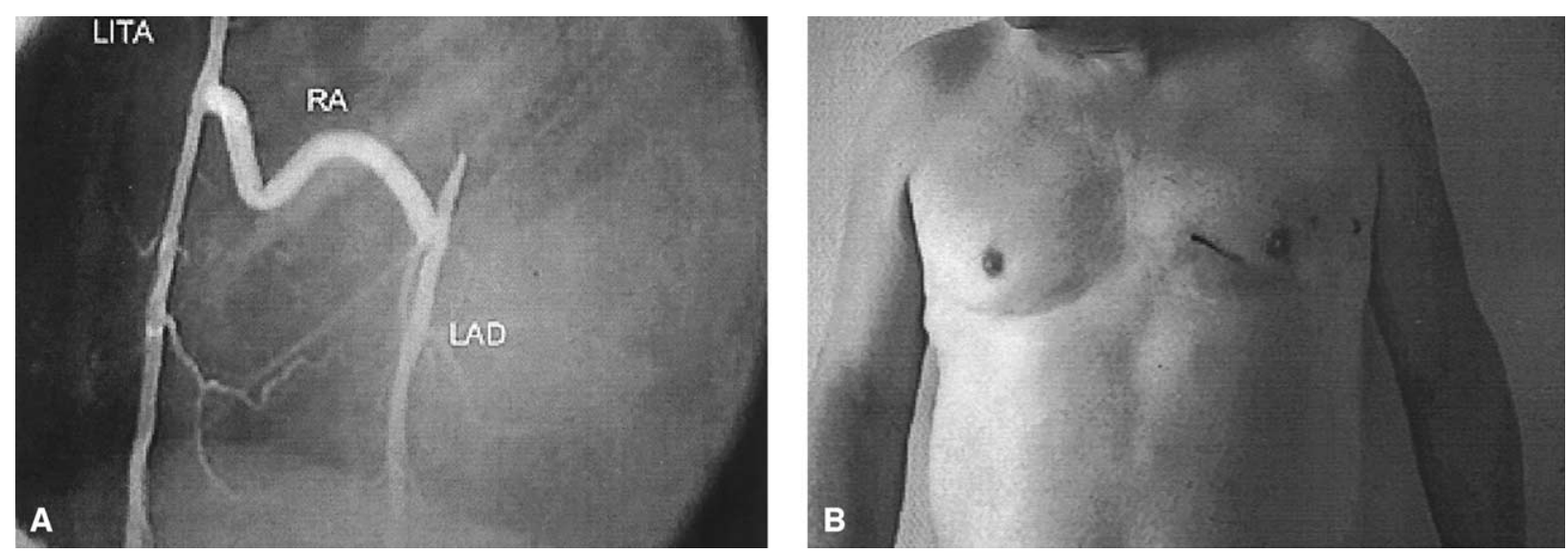

Figure 1. A, Postoperative coronary angiography after H-graft technique. $B$, Skin incision in H-graft technique.

\section{TABLE 2. Preservation solution}

\begin{tabular}{lc}
\hline Verapamil & $10 \mathrm{mg}$ \\
Nitroglycerin & $10 \mathrm{mg}$ \\
Sodium bicarbonate $8.4 \%$ & $10 \mathrm{~mL}$ \\
Heparin & $1000 \mathrm{IU}$ \\
Ringer solution (warm) & $600 \mathrm{~mL}$ \\
\hline
\end{tabular}

H-Graft technique. Two patients underwent grafting of the left anterior descending coronary artery (LAD) by use of a short segment of the left radial artery, which was attached proximally end to side to an in situ LITA (Figure 1, A). To dissect the left radial artery, we injected $1 \%$ lidocaine for additional sensory block of the arm. Radial artery was dissected through a small $5-\mathrm{cm}$ incision with standard technique. After systemic administration of 10,000 IU heparin, a 6- to 7-cm long radial artery was harvested and preserved in a special solution (Table 2). In the next step, a 5 -cm left anterior skin incision above the fourth rib was performed (Figure 1,B), and 5 to $6 \mathrm{~cm}$ of the rib was removed by extrapleural disarticulation at the chondrosternal joint. The removed rib was not reimplanted. The LITA lies right under the chondrosternal joint, so a $1.5-$ to $2.0-\mathrm{cm}$ segment of the vessel was exposed by retraction of the tissue only. The musculophrenic, superior epigastric, and all intercostal branches were left intact because there was no dissection of the internal thoracic artery from the thoracic wall. A small pericardiotomy medial to the LITA was performed carefully to avoid pneumothorax. The LAD was exposed with deep pericardial sutures, and the heart was stabilized with three epicardial pledgetarmed sutures. After temporary occlusion of the LAD with a proximal vessel control suture, a 7-mm medial arteriotomy was performed and the radial artery was sutured to the arteriotomy in end-to-side technique with a running 8-0 polypropylene suture (Prolene; Ethicon, Norderstedt, Germany). After completion of the anastomosis, LAD flow was restored, and the character of back bleeding through the radial artery was noted. In the next step, the radial artery was trimmed to the desired length, after which an anastomosis was constructed between the proximal radial artery end and the side of the in situ LITA at the area exposed. Local arterial control was obtained with microvascular clamps (Bulldog clamp; Aesculap, Tüttlingen, Germany) on the radial artery and on the LITA proximal and distal to the point of anastomosis. After completion of the anastomosis, the clamps were removed, a small intrapericardial chest tube was placed, and the wounds were closed.

Rib cage lifting. Two patients underwent $\mathrm{CABG}$ with the rib cage-lifting technique. ${ }^{21}$ A 7 -cm skin incision was performed starting $1 \mathrm{~cm}$ above the level of the xiphoid process coursing parallel and $1 \mathrm{~cm}$ above the left costal arch (Figure 2). A few centimeters of skin were undermined above and below the incision. The linea alba was left intact, and the rib cage was freed from its attachments to the rectus abdominis muscle. The rib cage was detached from the sternum by an inverted J-shaped ministernotomy, starting from the left edge of the xiphoid process and ending at the fifth intercostal space. A small pediatric sternal retractor (Aesculap) was used to lift the rib cage, and the LITA was harvested conventionally up to the level of the second intercostal space. The pericardium was opened, and stay sutures were placed into the left cavity of the pericardium and pulled upward and anteriorly through the incision. In this way the heart was elevated and the middle and distal parts of the LAD were exposed. The anastomotic site was stabilized without the use of a stabilization device by three pledget-armed sutures (4-0 SH-1, polypropylene) left and right of the anastomotic site. After proximal bleeding was controlled by vessel control suture with 4-0 SH polypropylene, a 7-mm arteriotomy was performed on the LAD. Back bleeding was controlled by a blower with carbon dioxide and saline solution. The LITA-LAD anastomosis was performed with 8-0 polypropylene suture in a continuous fashion. The sternum was closed with wires, and the wound was closed by standard technique.

Complete median sternotomy. In 10 patients we performed complete median sternotomy in the awake setting. The chest was opened with an oscillating saw, and particularly careful LITA dissection was necessary to avoid pneumothorax in the spontaneously breathing patient. For multivessel CABG, an additional radial artery graft was dissected with the adjunct of local anesthesia of the arm. After creation of a pericardial cradle, the target vessels were exposed with the aid of mechanical stabilization. Anastomoses were performed by standard beating-heart bypass technique, with proximal control of the target vessel and a blower 


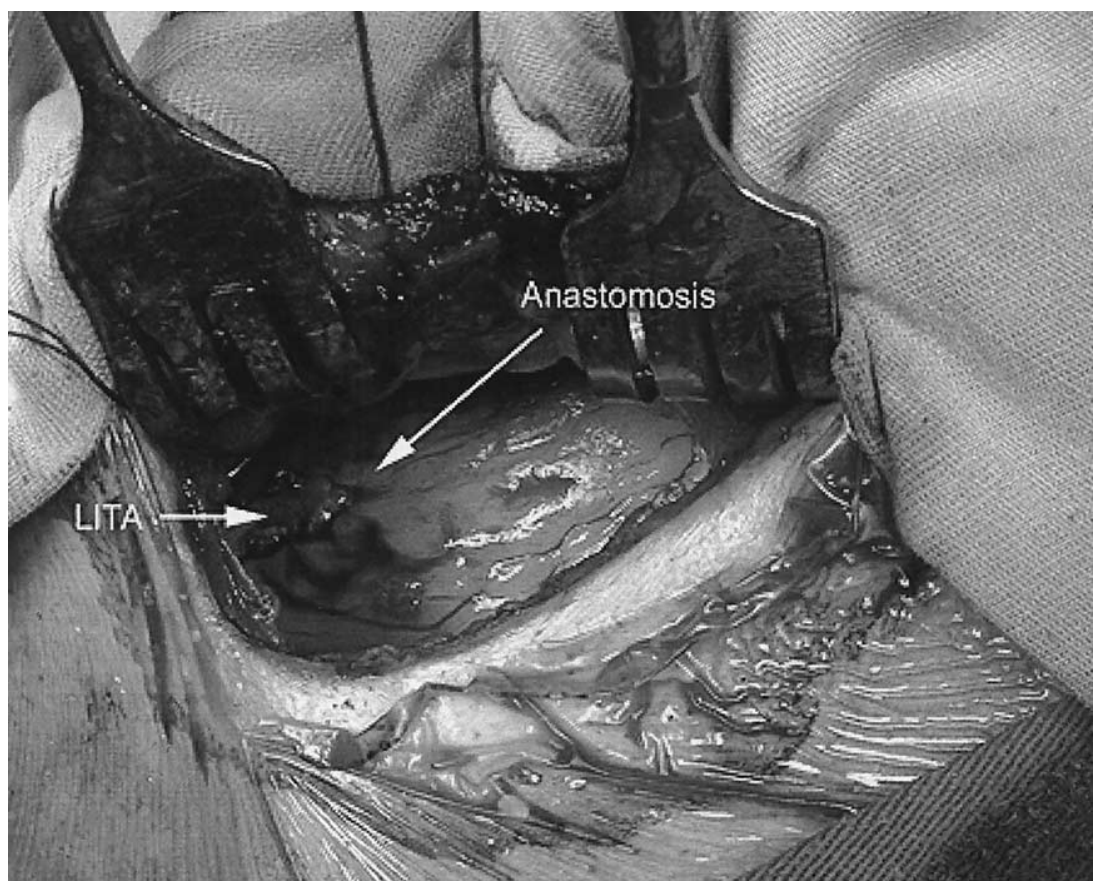

Figure 2. Operative situs during rib cage lifting (first described by Karagöz and associates ${ }^{\mathbf{1 0}}$ ).

mister to clear the anastomosis site. In 6 cases the LITA was anastomosed to the diagonal branch and the LAD. In 3 cases LITA-LAD as well as left radial artery-RCA anastomoses were performed. In 1 case triple revascularization was successfully established with LITA to LAD and the diagonal branch as a sequential graft as well as radial artery to the RCA (Table 3). For the LITA-LAD anastomosis, the heart was exposed with deep pericardial sutures between left and right lower lung veins. For the radial artery-RCA anastomosis, we used a wide, pledget-armed, U-shaped suture, which was placed at the acute margin of the heart and pulled toward the patient's left shoulder to expose the inferior surface of the heart. The anastomotic site of the RCA was chosen, and a 4-0 SH polypropylene suture was passed around proximally to the anastomotic site for control of the proximal bleeding and to expose the vessel with a small tourniquet. All peripheral anastomoses as well as the proximal anastomoses of the radial artery to the ascending aorta were performed with conventional technique.

\section{Anesthesia for ACAB}

High TEA was used. The objective of this approach was to achieve somatosensory and motor block at T1 to T8 level. The maximum permissible block level was $\mathrm{C} 6$, which was monitored by a possible development of Horner syndrome. One of the major objectives was to achieve motor block of the intercostal muscles while preserving diaphragmatic respiration.

Antiplatelet therapy was stopped 5 days before surgery in all cases. One day before elective surgery, a thoracic epidural catheter (Perifix Soft 505; B. Braun Melsungen AG, Melsungen, Germany) was inserted at T2 to T3 level (Figure 1). On the day of surgery patients were premedicated with $7.5 \mathrm{mg}$ of medazepam hydrochloride (INN: medazepam; Temmler Pharma GmbH \& Co. KG,

\section{TABLE 3. Operative data}

\begin{tabular}{lc}
\hline Procedure time (min, \pm SD) & $90 \pm 31$ \\
$\quad$ Minimally invasive direct CABG & $72 \pm 9$ \\
Off-pump CABG & $117 \pm 34$ \\
Anastomoses (No., mean \pm SD) & $1.4 \pm 0.7$ \\
Conversion to intubation (No.) & $3 / 34$ \\
Extubation in operating room (No.) & $3 / 34$ \\
Chest tube drainage (mL, \pm SD) & $150 \pm 49$ \\
Recovery room stay (h, mean \pm SD) & $4.2 \pm 0.6$ \\
Intensive care unit stay (h, mean \pm SD) & - \\
Hospital stay (d, mean \pm SD) & $6.8 \pm 2.2$ \\
Pain visual analog scale score (0-100, mean \pm SD) & $30 \pm 6$ \\
Need for anelgesia within 3 d & \\
$\quad$ Piritramide (Dipidolor, mg, mean \pm SD) & $0.7 \pm 2.2$ \\
Diclofenac (mg, mean \pm SD) & $35 \pm 42$ \\
Activities of daily living (day of surgery) & $22 / 34$ \\
\hline
\end{tabular}

Marburg, Germany) by mouth. In the operating room an infusion of $0.5 \%$ ropivacaine (AstraZeneca $\mathrm{GmbH}$, Wedel, Germany) with sufentanil at $1.66 \mu \mathrm{g} / \mathrm{mL}$ (Janssen Cilag, Neuss, Germany) into the epidural space was started. Sensory level was tested every 5 minutes. Thus sensory block was achieved between the neck and the abdomen, including both arms. Patients breathed oxygen at 5 $\mathrm{L} / \mathrm{min}$ by face mask. Monitoring included arterial and central venous blood pressure measurement, electrocardiography (leads II, $\mathrm{aVF}$, and $\mathrm{V}_{5}$ ), pulse oximetry, and end-tidal carbon dioxide measurement. The thoracic epidural catheter was used for not only intraoperative but also postoperative pain management for 3 days. Depending on pain perception, patients received additional analgesics, as routinely used in our department; all analgesics and sedative hypnotic agents are available in our department (Table 3). 


\section{Results}

Twenty-four patients underwent single-vessel CABG, 9 patients underwent double-vessel CABG, and 1 patient underwent triple-vessel CABG. TEA was used for perioperative analgesia, and patients were conscious throughout the procedure without any intravenous sedatives or analgesia. Three patients in this series required secondary intubation after completion of internal thoracic artery harvesting because of incomplete analgesia of the upper chest $(n=1)$ or pneumothorax $(\mathrm{n}=2)$, with consequent coughing and chest discomfort. These patients, who had a single ITA graft to the LAD through a partial lower sternotomy and low preoperative risk factors, were extubated in the operating room after the procedure. Mean length of skin incision was 7.4 \pm $0.8 \mathrm{~cm}$ in the partial lower sternotomy group $(\mathrm{n}=20), 5 \mathrm{~cm}$ in the H-graft group $(\mathrm{n}=2)$, and $7 \mathrm{~cm}$ in the rib cage-lifting group $(\mathrm{n}=2)$. Operative data are shown in Table 3. A total of $1.4 \pm 0.7$ anastomoses per patient were performed.

There were no significant increases in cardiac enzymes 6 hours after surgery (CK of $72 \pm 15 \mathrm{IU} / \mathrm{L}$ and CK-MB of 6.2 $\pm 2.4 \mathrm{IU} / \mathrm{L})$. Mean troponin T levels amounted to $0.09 \pm$ $0.02 \mathrm{ng} / \mathrm{mL}$. Preoperative renal function did not change after the operation (mean postoperative creatinine was 1.3 $\pm 0.5 \mathrm{mg} / \mathrm{dL}$ ). Reference levels are as follows: $\mathrm{CK}<80$ IU/L, CK-MB $<9$ IU/L, and cardiac troponin $\mathrm{T}<0.10$ $\mathrm{ng} / \mathrm{mL}$. Perioperative electrocardiographic monitoring with automatic ST-segment analysis displayed no signs of myocardial ischemia within the first 6 hours. The postoperative monitoring phase in the recovery room amounted to $4.2 \pm$ 0.6 hours. Patients remained hospitalized for $6.8 \pm 2.2$ days. There were no postoperative deaths. No patients had any spinal complications caused by placement of the epidural catheter. Transient Horner syndrome was observed in 2 patients.

Because of the continuous analgesic drug application through the epidural catheter for 3 postoperative days, pain perception was very good (visual analog scale score of $30 \pm$ 6). Effective pain management resulted in faster postoperative mobilization (Table 3 ).

Anastomoses were examined for quality by coronary angiography before discharge in 25 cases. Multidetector computed tomography was used to examine graft patency in 9 cases. All grafts showed good function, except for one proximal ITA occlusion.

\section{Discussion}

TEA provides excellent conditions for off-pump coronary artery bypass surgery by dilating the coronary arteries and the internal thoracic artery and by reducing heart rate and arrhythmias during manipulation of the heart. ${ }^{22-24}$ In addition to these intraoperative advantages, postoperative pain management is facilitated by continuous epidural application of analgesia. Such effective pain management improves postoperative mobilization and recovery after beating-heart surgery. ${ }^{6,10,11}$ A recent meta-analysis calculated the risk for epidural hematoma formation in cardiac surgical patients with a $95 \%$ confidence to be less than 1 of 150,000 for epidural anesthetics, ${ }^{14}$ compared with an incidence of $1: 143,000$ in the overall population receiving epidural anesthesia. ${ }^{15}$ In addition, somatosensory block of the thoracic segments enables even complete sternotomy and CABG in the awake setting.

Common philosophies in conventional minimally invasive CABG surgery focus either on avoiding cardiopulmonary bypass ${ }^{1,2,4}$ or on limiting surgical access ${ }^{3,16}$ to improve outcome. The aspect of avoidance of general anesthesia and positive-pressure ventilation for CABG performed through a complete sternotomy constitutes a new quality of trauma reduction. Because the patient stays awake throughout the epicardial stabilization, hemodynamic compromise and neurologic function during this critical period can be monitored easily. Thus the individual blood pressure threshold for each patient can be identified precisely. In anesthetized patients, this level remains unknown (usually a blood pressure $\geq 80 \mathrm{~mm} \mathrm{Hg}$ is considered mandatory). Our clinical results ${ }^{10,11}$ are supported by the reports of other groups who have presented initial positive experiences with $\mathrm{ACAB} .{ }^{17} \mathrm{We}$ therefore believe that $\mathrm{ACAB}$ is an promising adjunct to current minimally invasive $\mathrm{CABG}$ techniques. Another impact overall on the CABG patient population could be a potential use of this procedure in a hybrid setting.

The H-graft technique was developed by Cohn and associates $^{25}$ to minimize surgical access and reduce costal retraction. It is considered to be suitable for the awake setting because there is no necessity for complete internal thoracic artery dissection and thus opening of the pleural cavity. The operative time also seems to be shorter, and this is an important factor for the awake technique. Although the long-term patency of the radial artery as a free graft has not been demonstrated, favorable early and midterm results have been achieved with this conduit for $\mathrm{CABG}{ }^{26}$

The disadvantages of the procedure are a second incision for harvesting of the radial artery and a second anastomosis for the attachment of the free graft to the LITA. The most relevant possible disadvantage is the potential for diversion of significant LITA flow to noncoronary vascular beds, representing some variant of a steal syndrome. However, coronary perfusion mainly takes place during diastole because of pressure decrease below systemic diastolic pressure, even down to zero. ${ }^{27}$ This pathophysiologic mechanism of coronary perfusion is supported by the clinical observation that side branches of the internal thoracic artery shrink in size and noncoronary distribution becomes less important, as noted by Karagöz, who demonstrated this phenomenon in more than 50 angiograms after H-grafting (unpublished data). 
Further evolution of awake techniques led to the rib cage-lifting method to perform LITA-LAD grafting. ${ }^{8,16}$ For this approach a submammary skin incision is used to harvest the LITA. This technique allows extrapleural dissection of the LITA and good exposure of the LAD. This modified incision is especially suitable for female patients because of its better cosmetic result. On the other hand, the use of a rib cage retraction may cause increased pain in the high abdomen through traction of the muscles in a patient breathing spontaneously, which limits the use of this technique. Difficulties in the LITA dissection proximally result in a mobilization of the graft only up to the second or third intercostal space and carry the risk of a potential steal syndrome as well.

The latest technique for awake LITA-LAD grafting is partial lower sternotomy. This approach provides good access to the entire course of the LITA. The pleural cavity is not opened, so spontaneous respiration during surgery is not impaired. Furthermore, a conversion to full sternotomy, which was not required in this cohort, is much easier than with small thoracotomy approaches. The incision can be easily and rapidly extended to a full sternotomy if technical problems are encountered or the exposure is not adequate, in contrast to left anterior small thoracotomy approach, $\mathrm{H}$ graft technique, or rib cage lifting, which require an additional incision that leads to a less acceptable cosmetic result. Furthermore, performing LAD revascularization is faster through a partial lower sternotomy than through the left anterior small thoracotomy procedure. ${ }^{28,29}$ The entry into the chest cavity through the left anterior small thoracotomy approach constitutes a compromise between internal thoracic artery dissection and access to the LAD. It usually exposes only few segments of the LAD, whereas in the partial lower ministernotomy technique the whole course of the vessel is exposed. ${ }^{27,30}$ Moreover, left anterior small thoracotomy inevitably causes pneumothorax, which impairs spontaneous breathing. A potential major disadvantage of this technique is the risk of mediastinitis and sternal infection.

ACAB through a complete sternotomy is an alternative method for coronary artery revascularization that extends the previously described small access techniques. Complete sternotomy provides ideal access to all regions of the heart and neighboring structures, enabling the surgeon to perform complete operative revascularization similar to standard offpump CABG . In this series double or triple CABG was performed with arterial grafts, which carry better long-term prognosis, while the patients were conscious. With this anesthetic technique other types of cardiac or thoracic procedures, beyond coronary artery surgery may be possible. Revascularization of the circumflex territory is in most cases difficult because of hemodynamic impairment associated with exposing the vessel. In this early report we ini- tially selected patients with two-vessel disease (LAD, RCA) to avoid possible complications. After gaining further experience with the technique, we even expect to be able to perform right circumflex revascularization.

We recommend the H-graft technique for elderly and high-risk patients because it is a fast procedure that avoids intercostal retraction. In younger patients, partial lower sternotomy or the rib cage-lifting technique should be used to provide patients the benefits of the internal thoracic artery graft, such as long-term patency. The rib cage-lifting technique is particularly suitable for female patients because of its better cosmetic result.

It is our impression that patient comfort is improved substantially by avoiding general anesthesia and mechanical ventilation. There was no need to keep these patients in the intensive care unit. Rapid postoperative mobilization and faster recovery as a result of continuous application of pain medication through the thoracic epidural catheter shortens hospitalization time and may open the door for outpatient CABG surgery even for multivessel coronary artery disease. Local reimbursement regulations in Germany currently require a minimum hospital stay to obtain a flat fee for CABG. From a medical point of view, however, all ACAB patients could have been discharged within 3 days after surgery.

On completion of the learning curve, randomized controlled trials are mandatory to elucidate the relative importance of sole TEA in cardiac surgery. A limitation of this study is that it was an observational study dealing with technical issues and not a randomized study comparing different subgroups of patients. In this context, the ethical question remains as to what extent an awake patient can endure the psychologic stress of such an operation. On the basis of our experiences, ACAB should only be used in highly selected, compliant, and mentally stable patients with particular coronary stenosis who do not require permanent anticoagulation or preoperative antiplatelet therapy.

This report demonstrates the feasibility and safety of $\mathrm{ACAB}$ with various operative techniques in a small patient group. ACAB achieved excellent patient acceptance by avoiding general anesthesia and allowing effective pain management. With further refinement of the procedure, outpatient CABG may become feasible. The combination of the benefits of beating-heart CABG without cardiopulmonary bypass, a small incision, avoidance of general anesthesia, positive-pressure ventilation, and effective pain management may allow ACAB to compete with interventional catheter-based techniques.

\section{References}

1. Kirklin JK, Westaby S, Blackstone EH, Kirklin JW, Chenoweth DE, Pacifico AD. Complement and damaging effect of cardiopulmonary bypass. J Thorac Cardiovasc Surg. 1983;86:845-57.

2. Kirklin JK, Blackstone EH, Kirklin JW. Cardiopulmonary bypass: studies on its damaging effects. Blood Purif. 1987;5:168-78. 
3. Calafiore AM, Vitolla G, Iovino T, Iaco AL, Mazzei V, Commodo M. Left anterior small thoracotomy (LAST): mid-term results in single vessel disease. J Card Surg. 1998;13:306-9.

4. Diegeler A, Matin M, Falk V, Battellini R, Walther T, Autschbach R, et al. Coronary bypass grafting without cardiopulmonary bypasstechnical considerations, clinical results, and follow-up. Thorac Cardiovasc Surg. 1999;47:14-8.

5. Fawcett WJ, Edwards RE, Quinn AC, MacDonald IA, Hall GM. Thoracic epidural analgesia started after cardiopulmonary bypass. Adrenergic, cardiovascular and respiratory sequelae. Anaesthesia. 1997; 52:914-6.

6. Fillinger MP, Yeager MP, Dodds TM, Fillinger MF, Whalen PK, Glass DD. Epidural anesthesia and analgesia: effects on recovery from cardiac surgery. J Cardiothorac Vasc Anesth. 2002;16:15-20.

7. Kirno K, Friberg P, Grzegorczyk A, Milocco I, Ricksten SE, Lundin S. Thoracic epidural anesthesia during coronary artery bypass surgery: effects on cardiac sympathetic activity, myocardial blood flow and metabolism, and central hemodynamics. Anesth Analg. 1994;79:107581.

8. Loick HM, Schmidt C, Van Aken H, Junker R, Erren M, Berendes E, et al. High thoracic epidural anesthesia, but not clonidine, attenuates the perioperative stress response via sympatholysis and reduces the release of troponin $\mathrm{T}$ in patients undergoing coronary artery bypass grafting. Anesth Analg. 1999;88:701-9.

9. Scott NB, Turfrey DJ, Ray DA, Nzewi O, Sutcliffe NP, Lal AB, et al. A prospective randomized study of the potential benefits of thoracic epidural anesthesia in patients undergoing coronary artery bypass grafting. Anesth Analg. 2001;93:528-35.

10. Karagöz H, Sönmez B, Bakkaloglu B, Kurtoglu M, Erdinc M, Turkeli A, et al. Coronary artery bypass grafting in the conscious patient without endotracheal general anesthesia. Ann Thorac Surg. 2000;70: 91-6.

11. Vanek T, Straka Z, Brucek P, Widimsky P. Thoracic epidural anesthesia for off-pump coronary artery bypass without intubation. Eur J Cardiothorac Surg. 2001;20:858-60.

12. Aybek T, Dogan S, Kessler P, Neidhart G, Khan MF, WimmerGreinecker $\mathrm{G}$, et al. Complete arterial surgical revascularization through median sternotomy in awake patients. Z Kardiol. 2002;91: 238-42.

13. Aybek T, Dogan S, Neidhart G, Kessler P, Matheis G, WimmerGreinecker $\mathrm{G}$, et al. Coronary artery bypass grafting through complete sternotomy in conscious patients. Heart Surg Forum. 2002;5:17-21.

14. Ho AM, Chung DC, Joynt GM. Neuroaxial blockade and hematoma in cardiac surgery: estimating the risk of a rare adverse event that has not (yet) occurred. Chest. 2000;117:551-5.

15. Renck H. Neurological complications of central nerve blocks. Acta Anaesthesiol Scand. 1995;39:859-68.
16. Jegaden O, Mikaeloff P. Off-pump coronary artery bypass surgery. The beginning of the end? Eur J Cardiothorac Surg. 2001;19:237-8.

17. Tarhan S, Moffitt EA, Taylor WF, Giuliani ER. Myocardial infarction after general anesthesia. JAMA. 1972;220:1451-4.

18. Geissler HJ, Holzl P, Marohl S, Kuhn-Regnier F, Mehlhorn U, Sudkamp M, et al. Risk stratification in heart surgery: comparison of six score systems. Eur J Cardiothorac Surg. 2000;17:400-6.

19. Bodian CA, Freedman G, Hossain S, Eisenkraft JB, Beilin Y. The visual analog scale for pain: clinical significance in postoperative patients. Anesthesiology. 2001;95:1356-61.

20. Trzcieniecka-Green A, Steptoe A. The effects of stress management on the quality of life of patients following acute myocardial infarction or coronary bypass surgery. Eur Heart J. 1996;17:1663-70.

21. Karagöz H, Kurtoglu M, Özerdem G, Battaloglu B, Korkmaz S, Bayazit K. Minimally invasive coronary artery bypass grafting: the rib cage-lifting technique. J Thorac Cardiovasc Surg. 1998;116:354-6.

22. Steneth R. Thoracic epidural analgesia in aortocoronary bypass surgery; hemodynamic effects and endocrine metabolism. Acta Anesthesiol Scand. 1994;38:826-39.

23. Tenling A, Joachimsson PO, Tyden H, Hedenstierna G. Thoracic epidural analgesia as an adjunct to general anaesthesia for cardiac surgery. Acta Anaesthesiol Scand. 2000;44:1071-6.

24. Blomberg S, Emanuelsson H, Kvist H, Lamm C, Ponten J, Waagstein $\mathrm{F}$, et al. Effects of thoracic epidural anesthesia on coronary arteries and arterioles in patients with coronary artery disease. Anesthesiology. 1990;73:840-7.

25. Cohn WE, Suen HC, Weintraub RM, Johnson RG. The "H" graft: an alternative approach for performing minimally invasive direct coronary artery bypass. J Thorac Cardiovasc Surg. 1998;115:148-51.

26. Bhan A, Gupta V, Choudhary SK, Sharma R, Singh B, Aggarwal R, et al. Radial artery in CABG: could the early results be comparable to internal mammary artery graft? Ann Thorac Surg. 1999;67:1631-6.

27. Korbuly DE, Formanek A, Gypser G, Moore R, Ovitt TW, Tuna N, et al. Regional myocardial blood flow measurements before and after coronary bypass surgery. A preliminary report. Circulation. 1975;52: 38-45.

28. Aybek T, Kessler P, Dogan S, Neidhart G, Khan MF, WimmerGreinecker G, et al. Awake coronary artery bypass grafting: utopia or reality ? Ann Thorac Surg. 2003;75:1165-70.

29. Niinami H, Takeuchi Y, Ichikawa S, Suda Y. Partial median sternotomy as a minimal access for off-pump coronary artery bypass grafting: feasibility of the lower end-sternal splitting approach. Ann Thorac Surg. 2001;72:1041-5.

30. Wimmer-Greinecker G, Matheis G, Dogan S, Aybek T, Kessler P, Moritz A. Patient selection for Port-Access multi vessel revascularization. Eur J Cardiothorac Surg. 1999;16(Suppl 2):S43-7. 